\title{
Application of Augmented Reality Technology to Access Facial Sunscreen Product Label Information
}

\author{
https://doi.org/10.3991/ijim.v16i02.27813 \\ Thanakorn Uiphanit ${ }^{(\varpi)}$, Thatsanan Chutosri, Pongpisid Liangyoo, \\ Natcha Wattanaprapa, Pongsakorn Kingsuwankul, Wannarat Bunchongkien, \\ Phachaya Chiewchan \\ Faculty of Science and Technology, Suan Sunandha Rajabhat University, Bangkok, Thailand \\ thanakorn.uiessru.ac.th
}

\begin{abstract}
The goals of this study were to 1) examine the behaviors and demands of users who purchased face sunscreens online, and 2) build augmented reality technology for use in the present, 3) to determine the acceptance and satisfactory after using augmented reality technology to provide facial sunscreen data. This study included a sample group of 30 adults who purchased sunscreen for their faces. The results revealed that it had the highest average system use. Users are concerned with the clarity of the content presented on the screen, as well as the convenience and accessibility with which they may utilize the system. Because of the small size of the product labels on the package, they are difficult to read. Furthermore, consumers have expressed an interest in using the application. Because the use of AR technology to present information in a format that gives users a new experience and feel that they can easily access it. However, there may be constraints in terms of processing time and the display of data details while the data is processed. As a result, the system's performance is the worst of the bunch.
\end{abstract}

Keywords - augmented reality, facial sunscreen, access information, mobile users

\section{Introduction}

More and more individuals are turning their attention to the use of sunscreen these days because it is greatly beneficial. Sunlight does not harm the skin until it burns or develops dark patches hence, this process decreases the risk of skin cancer. Sunscreen ingredients protect the skin in a variety of ways, including by absorbing UV radiation and shielding the skin's layers. that has a rich color or reflects UV rays It will have detrimental consequences on the skin if it receives too much sunlight, such as red skin burns, freckles, sunburn, and aging skin from the sun. As a result, wearing tight clothing or carrying an umbrella may not be enough [17]. To avoid excessive sun exposure, use sunscreen when participating in the non-sun segment. By using a sunscreen with good characteristics, you can hide your protection. Sun protection of at least SPF 15 (SPF15) is recommended. 
In case long stay under the sunlight is unavoidable, specific sun cream with higher SPF value is crucially recommended. A proper sunscreen will protect your skin from both UVA and UVB radiation while also preventing inflammation. Protects skin from the sun's burning feeling and aids in the maintenance of a natural skin tone. The greater the SPF, the more visible it is. UV rays are also more effectively blocked by sunscreens [12]. Another key factor to consider before making a purchase is whether the product will suit the user's skin type. One should look over the ingredients to see if there are any compounds that should be avoided and determine whether the user is allergic to/ irritated by certain substances, such as alcohol, perfume, and parabens [10], as well as what type of skin the user has, such as normal, oily, dry, or combo skin, and then choose a product based on the condition for the best results on the user's skin [4].

The product label information on the container is written in a small font that is difficult to see, this may cause customers to select a sunscreen that is inappropriate for their skin type [3],[6]. As a result, the researchers devised a strategy to make it easier for consumers to obtain information on packaging. Using augmented reality technology, a mobile application may access sunscreen product label information for the face $[2],[5],[15],[8]$.

\section{Objective}

a. To research consumer behavior and demand for augmented reality technology for obtaining facial sunscreen product label information using a mobile application.

b. To develop augmented reality technology to present facial sunscreen information.

c. To evaluate the satisfaction study on the application of augmented reality technology to present sunscreen data for the face.

\section{Research conceptual framework}

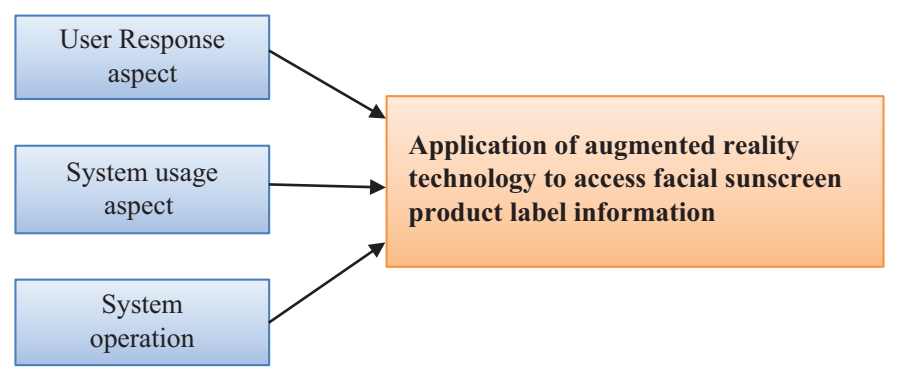

Fig. 1. The research conceptual framework model for application of augmented reality technology to access facial sunscreen product label information

Figure 1 presents the conceptual framework of this research, to show the procedure for using augmented reality technology to access facial sunscreen product label information. 


\subsection{Research design}

To develop mobile applications, this study used the SDLC (System Development Life Cycle) information system development cycle based on the Water Fall model and Augmented Reality [1],[7],[9],[14],[15]. This study used a sample of 30 buyers who used augmented reality technology to obtain information on facial sunscreen labels via a smartphone application.

\section{a. Data gathering}

Documents, papers, interviews, and survey reports were used to research the issues related to the sunscreen category, problems and conditions with the skin labels and packaging for sunscreen and exploring the behavior and demands for augmented reality technologies through the use of Augmented Reality. A survey of 30 face sunscreen purchasers' behaviors and demands for augmented reality technology to get facial sunscreen product label information via a mobile application revealed that: In the case of facial sunscreens, 96.7 percent are concerned about the components and would like to use augmented reality technology to get face sunscreen label information via a user's mobile application [2],[3].

\section{b. Design and development}

The researcher has concluded the work process of the mobile application in the following system flow diagram below.

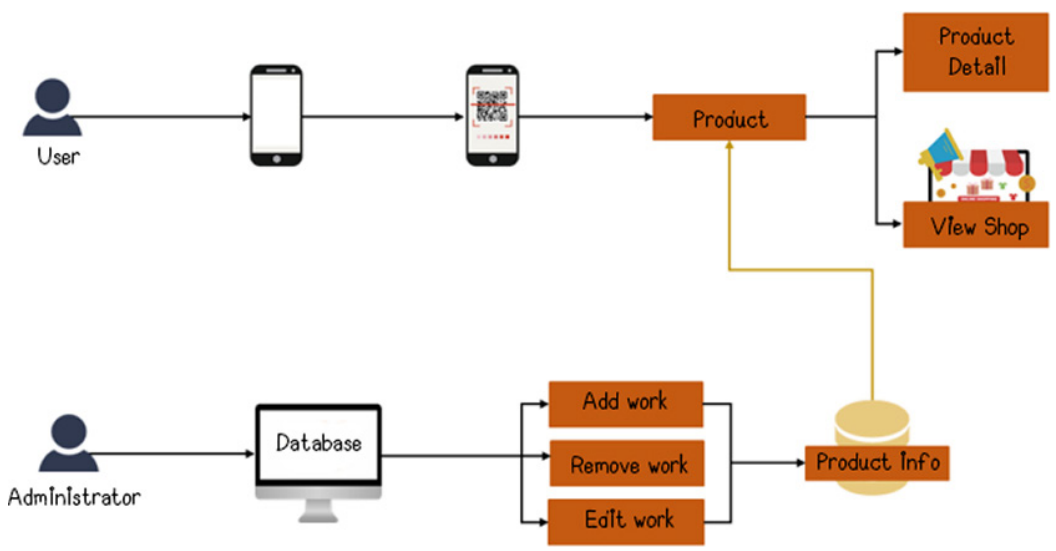

Fig. 2. System flow in the mobile application

The procedure for using augmented reality technology to display facial sunscreen information is shown in Figure 2. It is made up of user and administrator workflows that are arranged in a logical manner. This enables users to scan a QR code. The system uses augmented reality technology to deliver information in a user-friendly manner. Shoppers can also use the button to go straight to the store's page and place an order.

All screens and application components, including graphics, were created by the researcher with the following components; images, text, colors, buttons, a menu bar, and an interface for data input and output: 


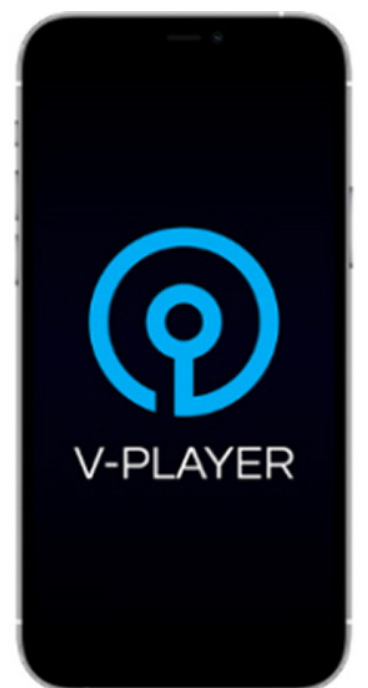

Fig. 3. Install application V-player to view the information

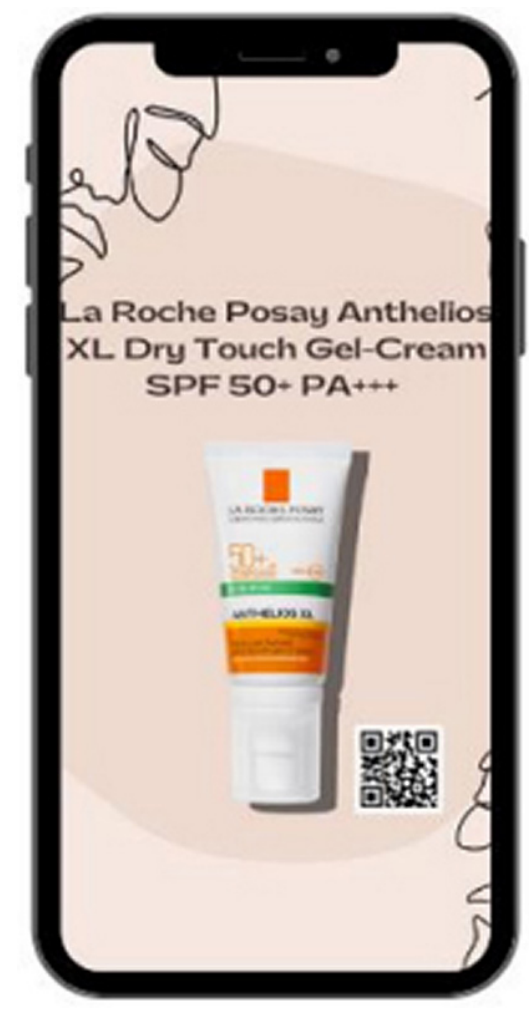

Fig. 5. Scanning QR to view information on the label

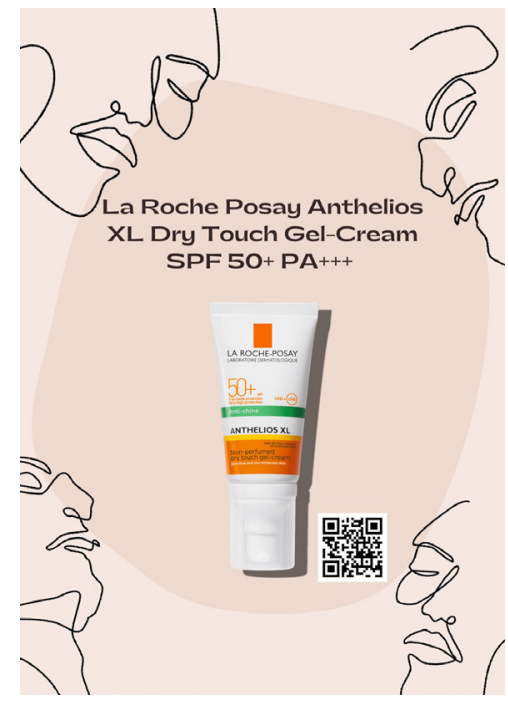

Fig. 4. Image and marker for scan

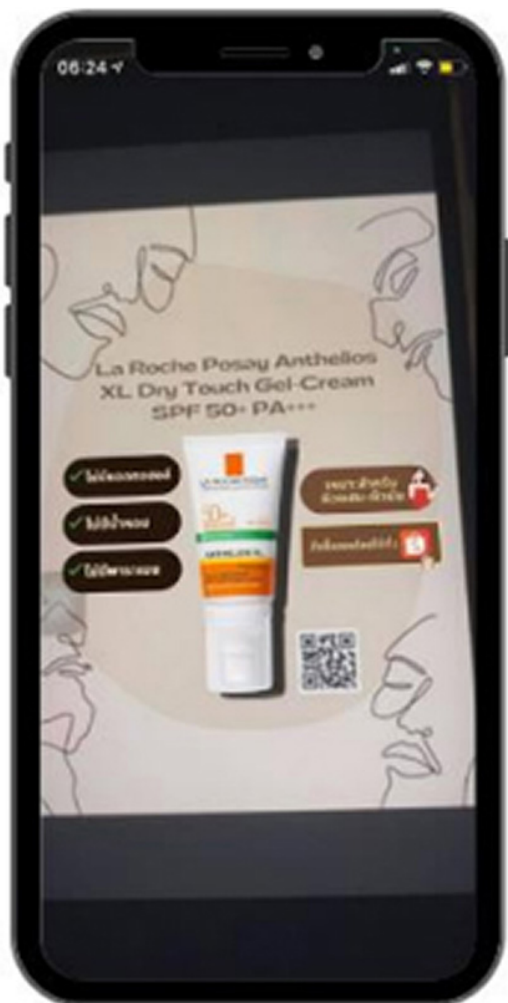

Fig. 6. Page displaying AR technology 
c. Implementation

The research has been done on the sample group of 30 people.

d. Evaluation

The researchers assessed the satisfaction study on applying augmented reality technology to present sunscreen data for face using an assessment form and a questionnaire.

The satisfaction score is a Likert scale with 5 levels, ranging from 1 to 5 . The meaning of each score is listed below so that the analysis of customers satisfaction can be performed [16].

$$
\begin{aligned}
& 1.00-1.49=\text { Not Suitable } \\
& 1.81-2.60=\text { disagree } \\
& 2.61-3.40=\text { neither agree nor disagree } \\
& 3.41-4.20=\text { agree } \\
& 4.21-5.00=\text { strongly agree }
\end{aligned}
$$

\section{$4 \quad$ Findings}

\begin{tabular}{|c|c|c|c|c|}
\hline No & Question & Mean & S.D. & Interpreted \\
\hline \multicolumn{5}{|c|}{ User Response Aspect } \\
\hline 1 & Stability of AR display & 4.33 & 0.58 & strongly agree \\
\hline 2 & Accuracy of AR display & 4.33 & 0.58 & strongly agree \\
\hline \multirow[t]{2}{*}{3} & Simplicity of the usage & 4.67 & 0.58 & strongly agree \\
\hline & Mean & 4.44 & 0.58 & strongly agree \\
\hline \multicolumn{5}{|c|}{ System Usage Aspect } \\
\hline 4 & Convenience and accessibility of accessing the system & 4.67 & 0.58 & strongly agree \\
\hline 5 & The clarity of the text displayed on the monitor & 4.67 & 0.58 & strongly agree \\
\hline \multirow[t]{2}{*}{6} & Appropriateness of the amount of information presented & 4.33 & 0.58 & strongly agree \\
\hline & Mean & 4.55 & 0.58 & strongly agree \\
\hline \multicolumn{5}{|c|}{ System Operation } \\
\hline 7 & Speed of the system accessibility & 4.00 & 1.00 & agree \\
\hline 8 & AR Processing & 4.33 & 0.58 & strongly agree \\
\hline 9 & Integrity of information & 4.00 & 1.00 & agree \\
\hline \multirow[t]{2}{*}{10} & Correctness of result display & 4.33 & 0.58 & strongly agree \\
\hline & Mean & 4.16 & 0.79 & agree \\
\hline
\end{tabular}

The researcher brought the developed mobile application to a trial group of 30 people and asked them to answer the questionnaire immediately after using the application. which can be summarized as shown in the table.

Table 1. Users preference and acceptance after using application 
In terms of system consumption, it has the highest average, as seen in the table above. Because people respect the system's ease of use and accessibility, as well as the clarity of the content presented on the screen [13]. As a result, product labels are small and difficult to read on packaging. Furthermore, consumers have expressed an interest in using the application. While in the user response aspect, the mean is in the second order because the use of AR technology to present information in a format that gives users a new experience and feel that they can easily access it. However, there may be limitations in terms of processing time and the display of details of the data waiting for some time. As a result, the system's performance is the least average.

\section{Discussion}

Even now, customers of facial sunscreens can get all of their information from the Internet. However, sunscreen for the face is a product that might cause allergic responses and other adverse effects when used. As a result, the group of purchasers must still go shopping and try out the product before making a purchase. As a result, the usage of mobile applications to display product label information using augmented reality technology has been approved because users still place a premium on readable font sizes and the ease with which they may obtain information via mobile devices. However, the extent of display for AR technology may be limited because it can't be read if it's not in the marker's region. Developing augmented reality technology for access to sunscreen product label information via mobile applications this time. Consider the ease of use and complete information on the product label. Creating a unique way of presenting information on product labels in order to market the product. It's also an easy and quick way to get product label information [18].

\section{Conclusions}

Most face sunscreen users prefer to purchase from www.facesunscreen.com which leads to the the goal of this study that is to employ augmented reality technology to access information on face sunscreen product labels via a mobile application. A place where things are sold so that you can try them out and get additional information before buying them, as well as read the product label. However, the label's letters are small, making it difficult to read. As a result, shoppers will be able to access information on product labels more readily and conveniently thanks to the usage of AR technology.

After experimenting with a sample group, the findings of using augmented reality technology to access information on product labels revealed that the system utilization aspect had the highest average because people respect the system's ease of use and accessibility, as well as the clarity of the content presented on the screen. Consequently, product labels are small and difficult to read on packaging. Furthermore, consumers have expressed an interest in using the application.

While in the user response aspect, the mean is in the second order because there is the use of AR technology to present information in a format that gives users a new experience and feel that they can easily access it. However, there may be limitations in 
terms of processing time and the display of details of the data waiting for some time. As a result, the system's performance is the least average.

AR remains a technology that gives shoppers a fresh impression and experience, making it easier for them to obtain label information and make purchasing decisions [11].

\section{$7 \quad$ References}

[1] Alan, D., Barbara, H. W., \& Roberta, M. R. (2012). Systems analysis and design. Hoboken NJ.: John Wiley \& Sons, Inc.

[2] Dunstone, K., \& Conway, C. (2014, December). There is an app for that! Communicating UV via the SunSmart app. In Proceedings of the NIWA UV Workshop (pp. 15-17).

[3] Gámbaro, A., Roascio, A., Boinbaser, L., \& Parente, E. (2017). Influence of packaging and product information on consumer perception of cosmetic creams-A case study. Journal of Sensory Studies, 32(3), e12260. https://doi.org/10.1111/joss.12260

[4] Gasparro, F. P., Mitchnick, M., \& Nash, J. F. (1998). A review of sunscreen safety and efficacy. Photochemistry and Photobiology, 68(3), 243-256.https://doi.org/10.1111/j.1751-1097. 1998.tb09677.x

[5] Giordano-Labadie, F. (2012). Cosmetic products: Learning to read labels. Eur J Dermatol, 22(5), 591-595. https://doi.org/10.1684/ejd.2012.1786

[6] Kong, B. Y., Sheu, S. L., \& Kundu, R. V. (2015). Assessment of consumer knowledge of new sunscreen labels. JAMA Dermatology, 151(9), 1028-1030. https://doi.org/10.1001/ jamadermatol.2015.1253

[7] Marneanu, I., Ebner, M., \& Roessler, T. (2014). Evaluation of augmented reality frameworks for android development. International Journal of Interactive Mobile Technologies, 8(4). https://doi.org/10.3991/ijim.v8i4.3974

[8] Nicholson, A., Murphy, M., Walker, H., Tinker, R., \& Dobbinson, S. (2019). Not part of my routine: A qualitative study of use and understanding of UV forecast information and the SunSmart app. BMC Public Health, 19(1), 1-9. https://doi.org/10.1186/s12889-019-7421-x

[9] Nuanmeesri, S. (2018). The augmented reality for teaching Thai students about the human heart. International Journal of Emerging Technologies in Learning, 13(6). https://doi.org/10.3991/ijet.v13i06.8506

[10] Panico, A., Serio, F., Bagordo, F., Grassi, T., Idolo, A., De Giorgi, M., ... \& De Donno, A. (2019). Skin safety and health prevention: an overview of chemicals in cosmetic products. Journal of Preventive Medicine and Hygiene, 60(1), E50.

[11] Rauschnabel, P. A., Felix, R., \& Hinsch, C. (2019). Augmented reality marketing: How mobile AR-apps can improve brands through inspiration. Journal of Retailing and Consumer Services, 49, 43-53. https://doi.org/10.1016/j.jretconser.2019.03.004

[12] Rassameekrittapas, V., \& Saknarong, A. (2019). Factors affecting consumer purchasing behavior of BIORE facial sunscreen in the Bangkok metropolitan area.

[13] Rese, A., Baier, D., Geyer-Schulz, A., \& Schreiber, S. (2017). How augmented reality apps are accepted by consumers: A comparative analysis using scales and opinions. Technological Forecasting and Social Change, 124, 306-319. https://doi.org/10.1016/j. techfore.2016.10.010

[14] Rodrigues, A. M., Sniehotta, F. F., Birch-Machin, M. A., Olivier, P., \& Araújo-Soares, V. (2018). Acceptability and feasibility of a trial testing allocation to sunscreen and a smartphone app for sun protection: Discontinued randomized controlled trial. JMIR Dermatology, 1(1), e1. https://doi.org/10.2196/derma.8608 
[15] Tellez, W. A., Nieto-Gutierrez, W., \& Taype-Rondan, A. (2017). Sunscreen mobile apps: A content analysis. European Research in Telemedicine/La Recherche Européenne en Télémédecine, 6(3-4), 157-163. https://doi.org/10.1016/j.eurtel.2017.08.001

[16] Uiphanit, T., Unekontee, J., Wattanaprapa, N., Jankaweekool, P., \& Rakbumrung, W. (2020). Using augmented reality (AR) for enhancing Chinese vocabulary learning. International Journal of Emerging Technologies in Learning (iJET), 15(17), 268-276. $\underline{\text { https://doi.org/10.3991/ijet.v15i17.15161 }}$

[17] Wang, S. Q., Balagula, Y., \& Osterwalder, U. (2010). Photoprotection: A review of the current and future technologies. Dermatology and Therapy, 23, 31-47. https://doi. org/10.1111/j.1529-8019.2009.01289.x

[18] Yim, M. Y., \& Chu, S. C. (2012). Extending the Electronic Technology Acceptance Model: Consumer Adoption of Augmented Reality-Based Marketing Tool. In AMA Summer Educators' Conference Proceedings (pp. 426-428).

\section{Authors}

Dr. Thanakorn Uiphanit is currently a lecturer in Department of Digital Innovation and Content Management, Faculty of Science and Technology, Suan Sunandha Rajabhat University, Bangkok, Thailand. E-mail: thanakorn.ui@ssru.ac.th

Thatsanan Chutosri is currently a lecturer in Department of Digital Innovation and Content Management, Faculty of Science and Technology, Suan Sunandha Rajabhat University, Bangkok, Thailand. E-mail: thatsanan.ch@ssru.ac.th

Pongpisid Liangyoo is currently a lecturer in Department of Digital Innovation and Content Management, Faculty of Science and Technology, Suan Sunandha Rajabhat University, Bangkok, Thailand. E-mail: pongpisid.li@ssru.ac.th

Natcha Wattanaprapa is currently a lecturer in Department of Digital Innovation and Content Management, Faculty of Science and Technology, Suan Sunandha Rajabhat University, Bangkok, Thailand. E-mail: natcha.wa@ssru.ac.th

Pongsakorn Kingsuwankul is currently a lecturer in Department of Digital Innovation and Content Management, Faculty of Science and Technology, Suan Sunandha Rajabhat University, Bangkok, Thailand. E-mail: pongsakorn.ki@ssru.ac.th

Wannarat Bunchongkien is currently a lecturer in Department of Digital Innovation and Content Management, Faculty of Science and Technology, Suan Sunandha Rajabhat University, Bangkok, Thailand. E-mail: wannarat.bu@ssru.ac.th

Phachaya Chiewchan is currently a lecturer in Department of Digital Innovation and Content Management, Faculty of Science and Technology, Suan Sunandha Rajabhat University, Bangkok, Thailand. E-mail: phachaya.ch@ssru.ac.th

Article submitted 2021-10-24. Resubmitted 2021-12-03. Final acceptance 2021-12-05. Final version published as submitted by the authors. 